\title{
EXCISION OF THE SHAFT OF THE TIBIA FOR SARCOMA
}

\author{
Examination Forty-three Years after Replacement by a Fibular Graft
}

\author{
Francisco Gextil, Lisbon, Portugal
}

On August 4, 1906, I resected the left tibial diaphysis of a girl aged fourteen vears for sarcoma diagnosed clinically and radiologically (Figs. 1 and 2). The segment excised was replaced by a graft of equal length from the fibula, the soft tissue attachments of which were disturbed as little as possible during mobilisation in order to preserve the blood supply. My reason for undertaking conservative resection was that the sarcoma was a central one, limited to the bone and showing no soft tissue invasion. Histological examination of the tumour showed a uniform structure. It consisted of connective-tissue spindle cells set in several directions, with an abundant vascular stroma. In several places, but mostly where the stroma was abundant and the fusiform cells scanty, there were groups of six or more giant cells. These were similar to the myeloplaxes of the bone marrow, from which they were probably derived. There were also some areas of degeneration, where the stroma was granular and its reaction-distinct from the acidophil reaction of the rest of the tumour-was basophil.

Since the first published report of this case in $\mathbf{1 9 0 7}$ it has been referred to by several writers, some of whom have doubted the accuracy of the diagnosis. Cavaillon and Alamartine

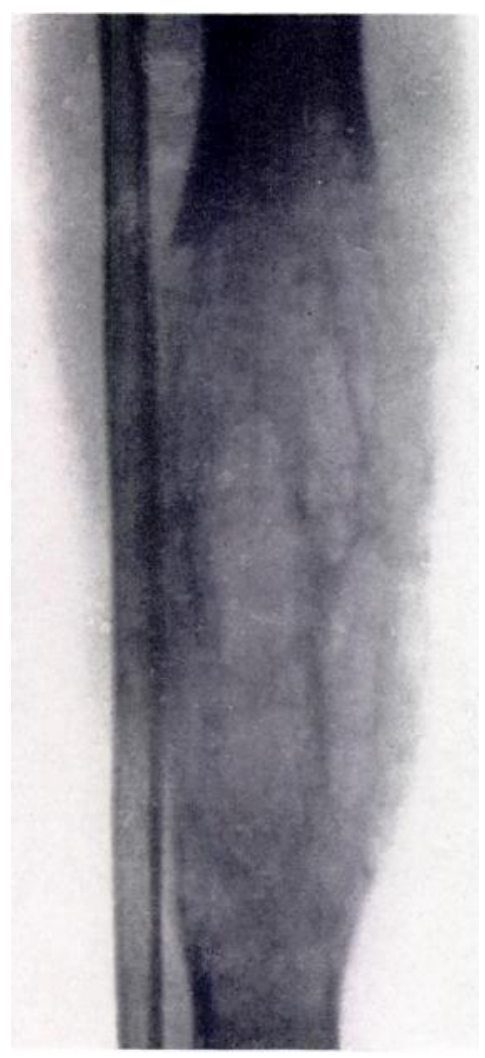

FIG. 1

The pre-operative radiograph taken in 1906 .

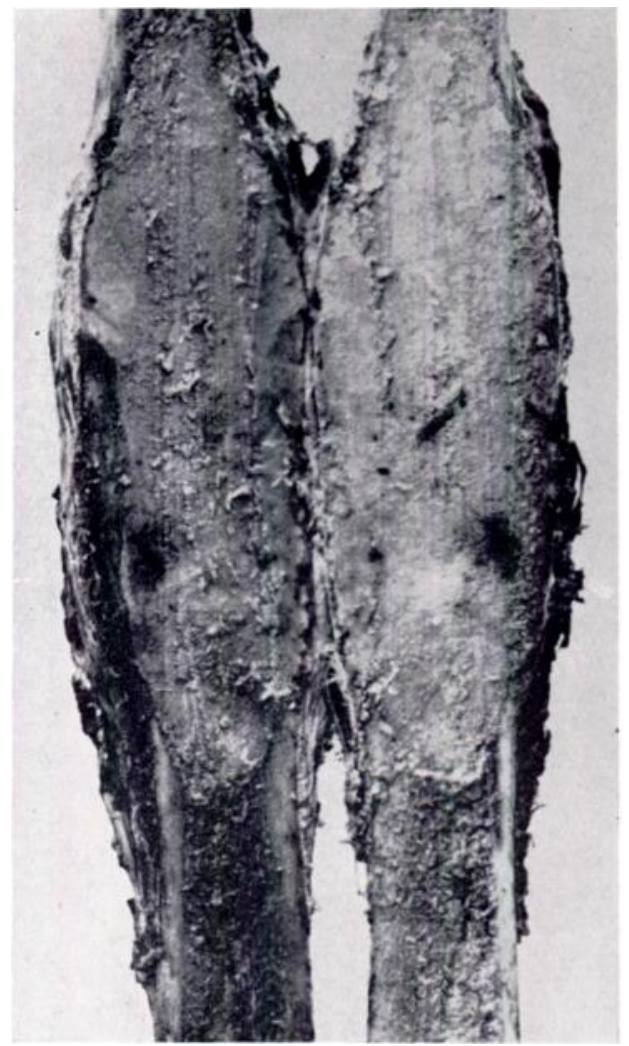

FIG. 2

The specimen after removal. 


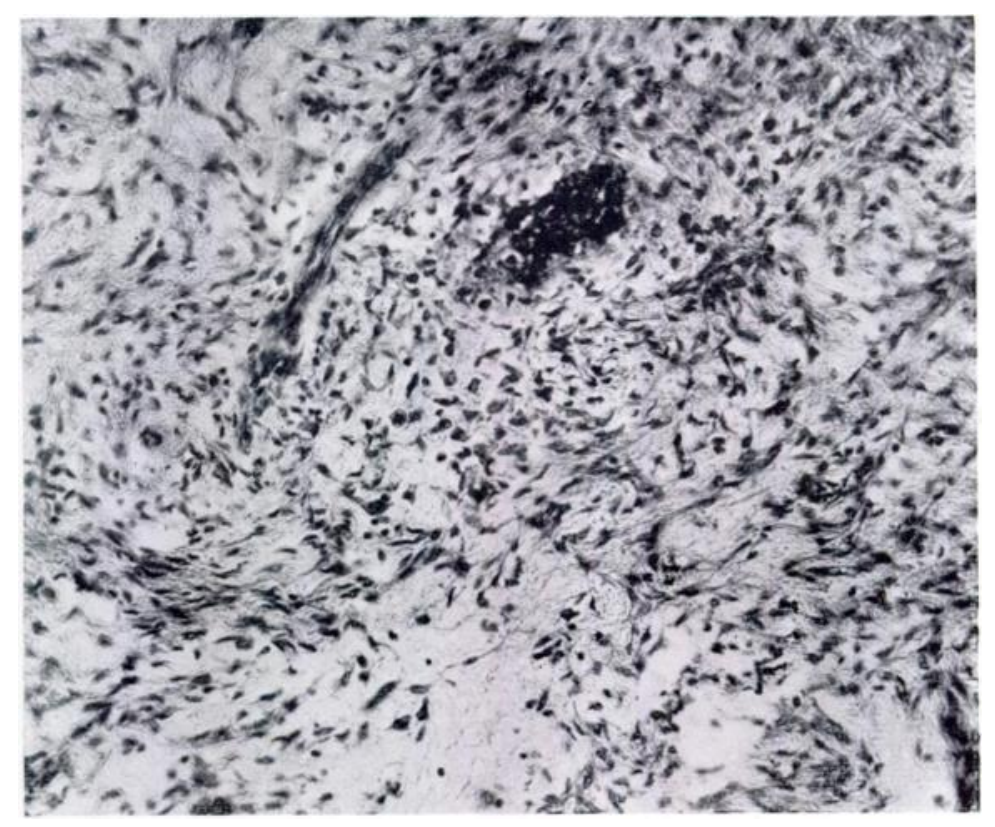

FIG. 3

A photomicrograph of the tumour taken in $1949(\therefore 75)$.

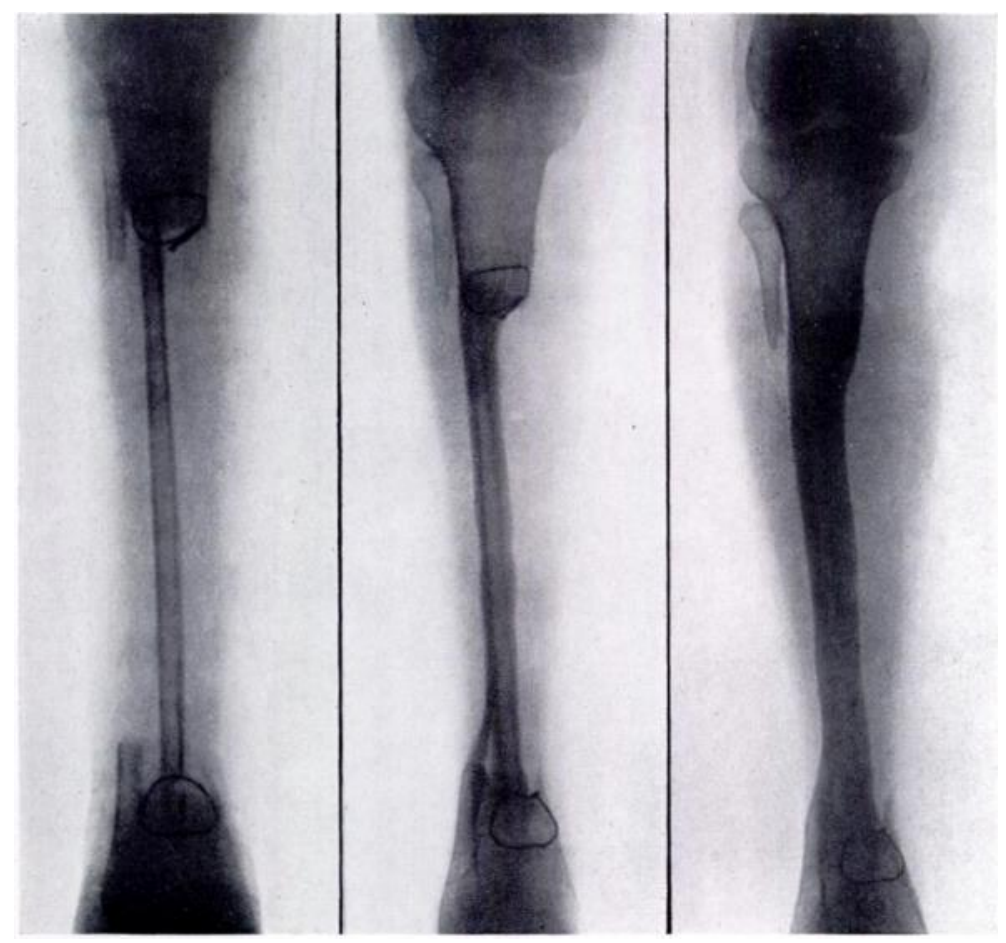

FIG. 4

Radiographs shortly after operation, and twenty and forty-three years later. 
(1909) and, more recently, Nové-Josserand and Tavernier (1927) have referred to the case as one of osteitis fibrosa.

For this reason we have re-examined the original material and have submitted the specimens for independent histological examination (Fig. 3). Professor Georges Gander reports: "Tumour of the tibial diaphysis, fusiform in shape, 23:5 centimetres long and 5 centimetres in diameter. The tumour invades the marrow and the bone as far as the periosteum. Histologically the tumour is composed of small fusiform or triangular cells with small nuclei, either round or elongated. Chromatin is atypical in quantity and distribution.

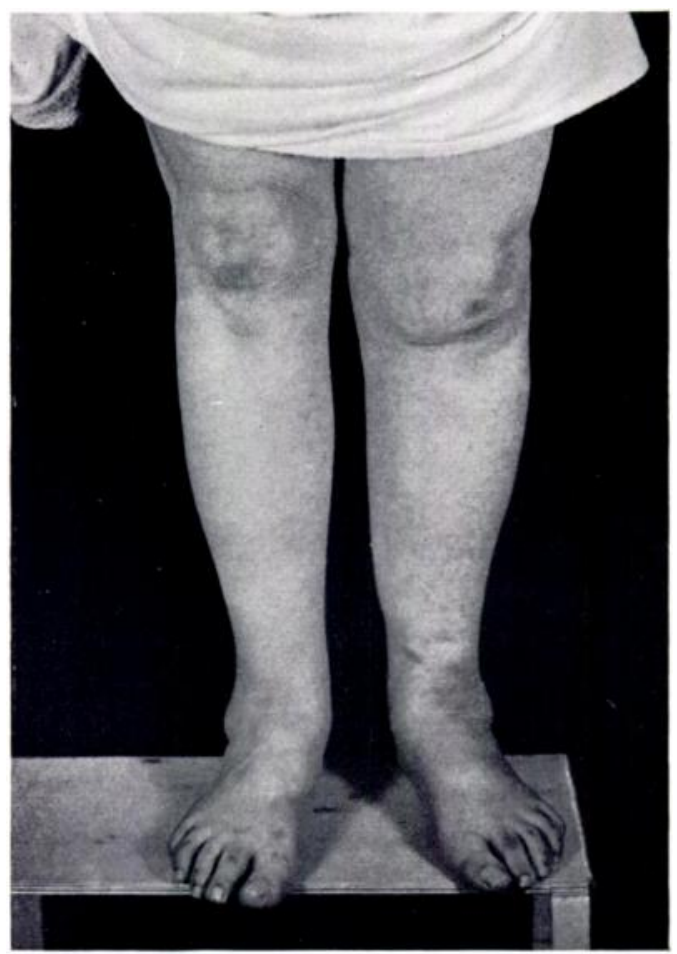

FIG. 5

The left leg forty-three years after operation.

Mitotic figures are numerous. In several places osteoid transformation of these elements is seen. In general the walls of the blood ressels are formed by tumour cells, endothelium being seldom present. In one place giant cells of osteoblastic type are seen. Areas of calcification are present in the osteoid tissue, and at some points there are groups of osteoblasts. It is a sarcoma of osseous origin and fibroblastic and osteoblastic type." This report confirms the original diagnosis of sarcoma; and it is worthy of note that resection and replacement by a fibular graft were successful.

Now, forty-three years after operation, the condition of the patient remains satisfactory. It is interesting to compare the radiographs taken immediately after the operation with others taken twenty and forty-three years later (Fig. 4). Walking is normal, and so, apart from some shortening, is the general appearance of the leg (Fig. 5).

\section{REFERENCES}

Cavallon, P., and Alamartixe, H. (19(19): Lyon Chirurgical, 2, 177.

(ientil, F. (1907): Gazeta dos Hospitais do Porto, No. 1, Anno 11.

Gentil, F. (1929): Lyon Chirurcical, 26, 465.

Nové-Josserand, G., and Tavernier, I. (1927): Tumeurs Malignes des Os. Paris: G. 1)oin et Cie.

vol. 32 B, No. 3, Algust 1950 